Article

\title{
Relationships among Environmental Attitudes, Risk Perceptions, and Coping Behavior: A Case Study of Four Environmentally Sensitive Townships in Yunlin County, Taiwan
}

\author{
Yung-Jaan Lee \\ Chung-Hua Institution for Economic Research, Division of Taiwan Economy, Taipei 106, Taiwan; \\ yungjaanlee@gmail.com
}

Received: 20 June 2018; Accepted: 25 July 2018; Published: 29 July 2018

\begin{abstract}
Climate change issues have attracted much attention in recent years. To date, the related research has focused mostly on the national and regional impacts of climate change. Taiwan, an island state, has relatively high vulnerability to the consequences of climate change, and its western coastal areas are particularly vulnerable. Yunlin County, with 13 townships that are all prone to flooding, will be highly affected by climate change. In this study, the 13 townships are grouped into four categories of synthesized vulnerability and ecological footprint (EF): "low synthesized vulnerability/low EF" (Linnei), "high synthesized vulnerability/low EF" (Sihu), "low synthesized vulnerability/high EF" (Mailiao), and "high synthesized vulnerability/high EF" (Huwei). Ecological footprint was used to measure the human demand for resources and ecological services, as well as a way to understand the relationships among human living habits, consumption patterns, and natural capital consumption. Then, the relationships among attitudes to climate change, risk perceptions, and coping behavioral intentions in these four categories were examined using structural equation models (SEM). A stratified random sampling method was used to collect 582 valid questionnaires. In addition to descriptive statistical analyses, the results of the SEMs for the four sensitivity categories indicate that different townships exhibit different causal relationships among attitudes to climate change, risk perceptions, and behavioral intentions. These findings can support appropriate strategies for governments, communities, and non-governmental organizations (NGOs) for ensuring that areas of various sensitivities can cope. However, more vulnerable townships exhibit no significant positive relationship between attitudes to and knowledge of climate change, place attachment, and their adaptation behavioral intentions in the face of disaster risk perceptions. Therefore, in areas with high vulnerability, special attention should be paid to making the residents improve their adaptive behavioral intentions in the face of disaster risk perceptions.
\end{abstract}

Keywords: vulnerability; ecological footprint; risk perceptions; structural equation model

\section{Introduction}

The environmental changes that arise from climate change have become a major issue globally [1-6]. The main effects are a large increase in the incidence of extreme weather events, changes in the global hydrological cycle, accelerated water vapor evaporation, increased intensity of precipitation, and increased frequency of heat waves [7]. According to the Intergovernmental Panel on Climate Change (IPCC) report, in the face of extreme weather, Asian countries may face flooding, high temperatures, and drought. However, countries can substantially reduce the damage caused by climate change by efficiently using land, improving early warnings of disasters, updating infrastructure, and reducing vulnerability [1]. 
In the last 20 years, population growth and economic development have had significant effects on climate change. Between 1997-2016, more than 524,000 people died as a result of over 11,000 extreme weather events, and total losses of approximately US\$3.16 trillion (at purchasing power parity) were incurred. In 2016, Haiti, Zimbabwe, and Fiji were the countries most affected directly by extreme weather events; Taiwan ranked seventh (from 51st in 2015). The number of deaths as a result of climate change in Taiwan in 2016 was 103, ranking 13th in the world; property losses of approximately US $\$ 1.978$ billion placed Taiwan 10th globally [8].

Various places and communities have been confronted with different issues related to climate change [7]. The international disaster risk-reduction community has long argued that reducing social vulnerability to hazards is a key element of sustainable development [9]. As climate change increases the probability of extreme weather events, from a socio-psychosocial perspective, processes that increase or mitigate preventive behavior in response to increased environmental risk must be understood. Recent studies have found that particular socio-psychological variables may influence individual perceptions of environmental risk, which may improve or impede the willingness of individuals to cope with impending environmental risks [10,11]. In fact, risk perception is one of the basic variables that predict preventive and coping behavior $[10,12,13]$

Taiwan, as an island state, faces frequent threats of extreme weather events. During the rainy season, typhoons and rainstorms cause flooding and geological disasters, which frequently result in severe soil and rock caving in hillside areas and debris flows in mountainous areas. The rising sea level causes flooding in coastal areas, where the intrusion of seawater and the difficulty of rainwater venting co-exist, resulting in severe agricultural and economic losses in central and southern regions, especially Yunlin County. Yunlin County is the main agricultural county in Taiwan. Long-term labor outmigration in the global economic development has made Yunlin County an aged society. Furthermore, in recent years, Yunlin County has been affected by climate change and the artificial overexploitation of groundwater, making the coastal townships prone to flooding and serious subsidence. In the face of "double exposure" [14-18], climate change mitigation and adaptation have become particularly important to the government.

The climate change issue has attracted much attention in recent years. Most of the research has focused on the impact of climate change from national and regional perspectives. Yunlin is a county in the western coast of Taiwan, which is an island state that will be strongly affected by climate change. Most of Yunlin County is a plain terrain, with the topography slowly increasing from west to east. The long-term use of groundwater (due to unstable surface water source) has caused serious subsidence in Yunlin. Moreover, the population of Yunlin County has shown negative growth for over 10 years, making it an aged society. These indicate that Yunlin County needs to review its social and welfare issues (such as aged population and the medical and elderly care derived from an aged society). Furthermore, the issue of labor force should not be neglected in relation to industrial development. Regarding the synthesized vulnerability, the biophysical vulnerability of land subsidence, drainage, and flood prevention in coastal areas should be examined. Social vulnerability, such as whether an area is an aged society and/or has a labor shortage, should be analyzed as well.

In view of Yunlin County's natural environment, the townships in Yunlin County can be classified into different categories of synthesized vulnerability based on their biophysical and social vulnerabilities. The most vulnerable townships are Kouhu, Sihu, and Yuanchang; the least vulnerable are Mailiao, Dounan, Shuilin, and Linnei (Figure 1). The ecological footprint can be used to measure human demand for resources and ecological services, as well as understand the relationship among human living habits, consumption patterns, and natural capital consumption [19]. The size of the EF is proportional to the impact on the environment; the larger the footprint, the greater the impact on the environment. Moreover, the size of the footprint is inversely proportional to the product of the biomass that can be used per person, and the larger the footprint, the smaller the area of the biomass that each person can use. Therefore, EF can be regarded as an indicator of people's consumption of the land's resources. A larger EF indicates a bigger consumption of the residents, and further induces a 
bigger impact on the environment. If individual EF is considered, the townships in Yunlin County can be grouped by sensitivity to environmental change (high synthesized vulnerability/high EF, low synthesized vulnerability/low EF). From the perspective of urban-rural resilience, if Yunlin County is to become climate-resilient, then whether climate change mitigation and adaptation can effectively reduce the impact of local climate change must be examined. Effectively reducing vulnerability to increase resilience depends on people's attitudes to climate change, risk perceptions, and coping behavior. Therefore, this study investigates the causal relationships among attitudes to climate change, risk perceptions, and coping behavior for townships in differently sensitive areas (regarding their synthesized vulnerability and ecological footprint) of Yunlin County.

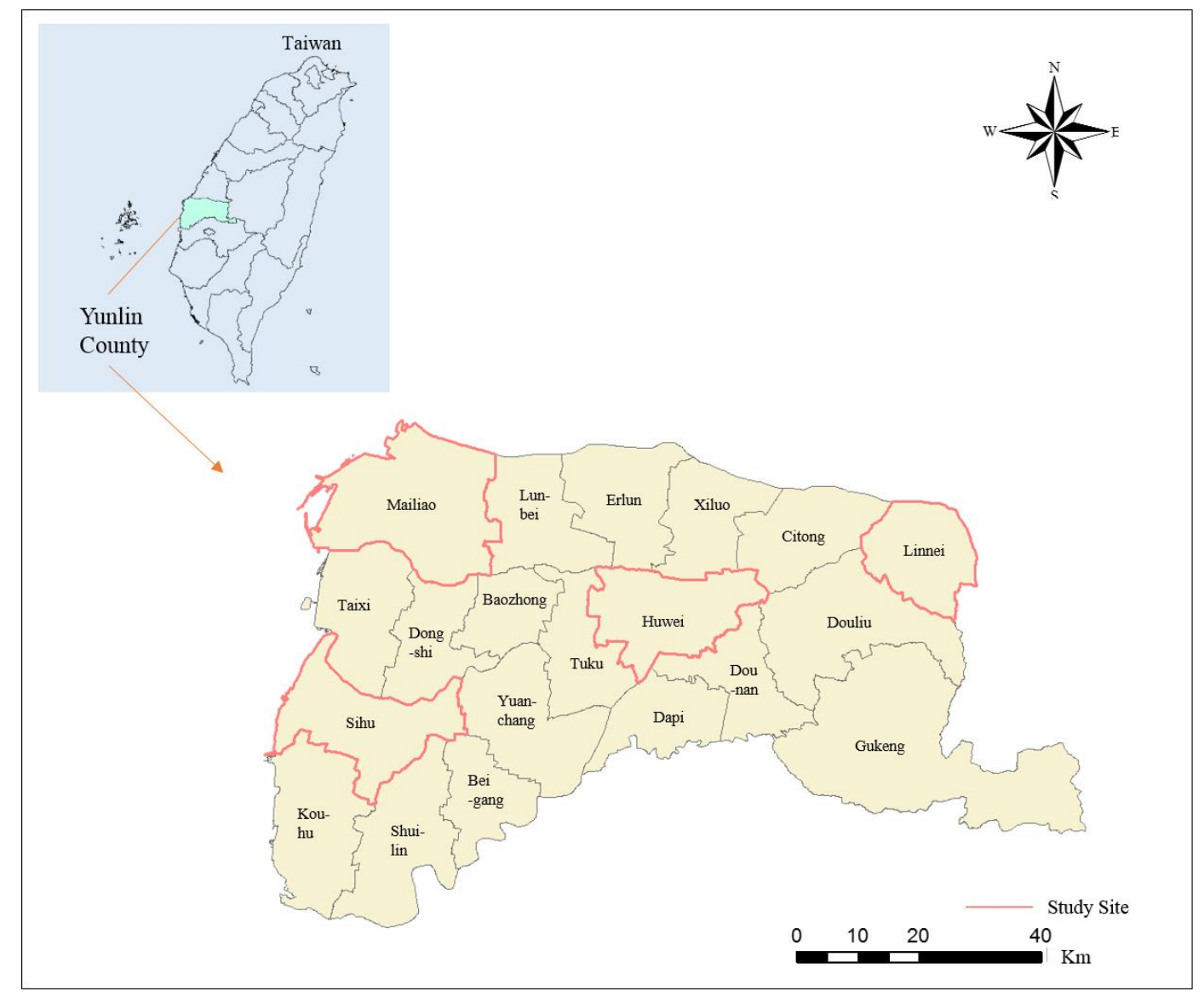

Figure 1. Yunlin County, Taiwan.

\section{Literature Review}

\subsection{Risk Perception}

Risk incorporates the severity of adverse effects and the likelihood of their occurrence [20]. An increasing number of empirical studies of disasters and hazards reveal that risks are not equally distributed or shared among all groups [21-23]. Risk perception refers to the identification of risks and the ability of individuals to identify them, and is an important predictive variable of coping behavior [12]. Risk perception is a cognitive and emotional response to situations or events that threaten their value. Cognitive response is an individual's knowledge of risks, whereas emotional response is emotional fluctuations, such as anxiety and worry [24]. Therefore, risk perception incorporates "risk knowledge" and "risk anxiety" concepts.

Risk is a subjective concept, and it is usually affected by personal background, culture, socio-economic status, and other factors. Therefore, an objective concept of risk is difficult to establish. 
The risks that are associated with natural disasters are commonly judged by their rate of occurrence. Since natural disasters typically occur at very low frequencies, people tend not to treat them as high-risk events; thus, their associated risks are frequently underestimated [25].

In the face of increasingly frequent disasters, the planning and implementation of disaster reduction actions have become indispensable. Raaijmakers et al. (2008) defined risk perceptions in terms of relationships among situational risk characteristics (awareness, anxiety, and preparedness). When a person has added an attribute of situational risk, his or her overall risk perception and resilience may increase. Accordingly, environmental risks can be defined separately or in relation to various contexts. In fact, many factors affect risk perceptions, including the frequency, severity, and direct/indirect experience of risk events [10].

Zhou and Shih (2000) found a strong positive correlation between risk perceptions and disaster reduction behavior [26]. Liao (2009) further suggested that since people have different risk perceptions with respect to both disaster prevention and risk reduction measures, policymakers must be aware of their population's perceptions of risk events and possible responses to risk events to provide effective risk management [27].

Risk perceptions are basic variables that predict preventive and coping behavior [12], particularly in relation to flooding [10,13], but they can be affected by place-specific biases (such as an optimistic bias with respect to environmental risk) [28-31]. Relevant studies have noted that place attachment may negatively mediate positive relationships, and this impeding effect is greater in areas with higher subjective risk [10].

\subsection{Place Attachment}

Place attachment is one of the most important socio-psychological aspects of interactions between humans and their environment [10,11,32-34]. "Place" is an important concept in human geography and related sciences such as environmental psychology and sociology, land-use planning, and architecture [34,35]. Its theories and empirical conceptualization arise from studies of the forcible evacuation of people from their places of residence [36]. Moreover, the concept of place attachment arises from the "attachment theory" of Bowlby (1988), who discussed the affect and emotion that bind people to places [37].

Place attachment (which is the emotional factor of an individual's place-specific local identity), based on "place-specific biases" [11,29,31,38,39], supports or impedes some place-related behavior $[10,28]$. Consequently, when people have emotional bonds with a place, they tend to overlook events in that place with low probabilities, even though they may have severe potential impacts [40-42]. Unfortunately, environmental risks (especially floods) are of this type [10].

Place attachment influences many environmental psychological processes that constitute the interaction between humans and the environment. However, no consensus exists regarding the role of place attachment in the relationship between environmental risk perceptions and coping behavior $[10,11]$. Owing to the obvious relationships between place attachment and individual place-specific identity, place attachment is assumed to have a negative moderating relationship between environmental risk perceptions and coping behavior $[10,43,44]$. Research suggests that greater perceived risk is associated with the greater willingness of people to cope with environmental risks, but the effect is weaker if place attachment is stronger. The development of an affect-based clue (such as place attachment) reduces environmental risk coping intentions and actions [45], if it is linked to high-risk perceptions [10].

\subsection{Climate Change Attitudes, Risk Perceptions, and Coping Behavior}

The United Nations Framework Convention on Climate Change, The eighteenth session of the Conference of the Parties (UNFCCC COP18) held in Qatar in 2012, announced the establishment of the "Doha Work Programme" to promote efficient international cooperation over climate change and better education about climate change by United Nations members. The Doha resolution refers to a 
goal of "education, training, and public awareness", the achievement of which is facilitated by the educational behavior of state-driven actions. The aforementioned UN convention and plan include advocacy for climate change education to affect people's attitudes and perceptions of climate change. However, people's responses to, and judgment of, climate change risks are affected by culture, social activities, and life experience. For example, Khima et al. (2012) found that Cambodian farmers lacked understanding of the impact of climate change on livelihoods in their communities [46].

Most of the research into the perceptions-attitudes-behavior relationships of the people has focused on perceptions and behavior associated with environmental conservation. Hong et al. (2012) found that a greater control of individual cognitive behavior corresponds to a stronger intention to save energy and reduce carbon emissions [47]. Greater control of subjective norms and pro-social behavior corresponds to a more positive attitude to energy-saving and carbon emission reduction, and a stronger behavioral intention to save energy and reduce carbon emissions. Greater awareness of energy-saving and carbon emission reduction does not necessarily lead to better attitudes; however, better attitudes to energy-saving and reducing carbon emission do lead to a stronger intention to save energy. At the same time, some investigations have found that perceptions do not influence relevant behavior, and that when a person lacks available resources or opportunities, despite having positive attitudes and subjective norms, their behavioral intention is reduced [48-50]. Yang and Lin (2010) predicted that stronger perceptions of the greenhouse effect are associated with more anti-greenhouse effect behavior. Yet, empirical results indicate that the residents of Taipei City exhibit no significant perceptions concerning behavior to mitigate the greenhouse effect [51].

People with sufficient environmental information and knowledge are commonly assumed to act accordingly, but studies have demonstrated that "information-to-action" associations are not linear, and no clear correlation exists. This may arise from the current methods of environmental improvement being overly focused on the provision of environmental information and knowledge, while ignoring environmental awareness [52]. However, in the face of increasingly significant climate change and unpredictable major disasters, Doswald and Osti (2011) believed that low-income areas are the most vulnerable to future climate change [53]. Halady and Rao (2010) found that in the drafting strategies for coping with climate change, stakeholders in a vulnerable community who are aware of the impact of climate change clearly differ from others [54].

\subsection{Place Attachment, Risk Perceptions, and Coping Behavior}

In summary, with the exception of a few studies of the relationships among place attachment, risk perceptions, and intentions in response to environmental risks [10,55-57], systematic empirical studies of the moderating role of place attachment in the relationship between environmental risk perceptions and coping intentions and behavior [10] (De Dominicis et al., 2015) are lacking. Owing to conflicting findings, the correlation between place attachment and environmental risk perceptions remains unclear. Some studies have shown a negative correlation between place attachment and risk perceptions. For example, Bucharest is one of the capitals with the highest possibility of risk in the world. Bucharest is predominantly vulnerable to hazards owing to the high population density, the obsolete infrastructure, the inefficient organization of civil protection, and the poor education of the inhabitants regarding seismic risk. Armas (2006) has suggested that strong emotional bonds (feelings for living areas) provide a sense of security [58]. However, they also produce a disregard for, or even outright denial of the existence of, Bucharest disasters, which are associated with earthquake risk. Conversely, people with a stronger attachment to their neighborhood have stronger flood risk perceptions and associated flood-related concerns, but this finding is based only on people who live in low-risk areas of Italy [55].

The above undue optimism (false expectation of positive results) is related to information processing bias and maladaptation [30]. Restated, relevant, and correct information is likely to be wrongly applied because of "affect-based bias" [59], resulting in procedural deficiencies and resistance [30], and ultimately a lack of adaptive behavior. In examples of the negative effects of 
attachment to place on human-environment interactions (a stronger attachment to place causes poorer coping behavior), the interaction of affect-based biases can be reasonably assumed to increase, making it a barrier to undertaking coping behavior [10].

In numerous studies of risk perceptions and optimism bias $[10,29,31,60]$, respondents who know more about risk prevention take more preventive action. Age may be the main driver of differences between risk perceptions and risk-related anxiety. A lack of knowledge of risk, traditional myths, and the effect on the risk-related anxiety of old people's personal experiences of disasters may make age the factor that most strongly affects place attachment, flood risk perceptions, and coping behavior. Accordingly, an increasing number of studies have been carried out to determine whether people in different age groups exhibit an optimism bias, which could be a barrier to, or a supportive factor in, perceptions of flood risk and coping behavior [10,11,43,60-62].

\subsection{Relationships among Place Attachment, Risk Perceptions, and Coping Behavior}

International organizations and governments are increasingly emphasizing the impacts of climate change. Taiwan is environmentally sensitive due to the geographical conditions of an island state. The vulnerable areas of the western coast of the island have a serious land subsidence issue, of which Yunlin County is the most serious one. Furthermore, Yunlin County is one of the most aged counties in Taiwan. Due to the dual vulnerability of biophysical and social vulnerability, coupled with the impact of $\mathrm{EF}$, there are different degrees of risks in townships of Yunlin County.

Therefore, this study elucidates the interactions of different synthesized vulnerability and EF in townships of Yunlin County. It further analyzes the causal relationship among risk and attitudes toward climate change, risk perceptions, and behavioral intentions, as well as the governance strategies of local government and community risk, in order to achieve the goal of building resilient urban and rural areas. It can be seen from the above literature review that there are numerous studies on the relationships among environmental perceptions, environmental behavior, risk, and resilience, but few studies integrate climate change attitudes, risk perceptions, place attachment, behavioral intentions, vulnerability, and EF. Therefore, this study, based on the literature review, proposes a causal relationship of climate change attitudes, risk perceptions, and behavioral intentions, and further carries out an empirical study in Yunlin County.

\section{Research Design}

\subsection{Questionnaire Survey}

This investigation examines the relationships among climate change attitudes, risk perceptions, place attachment, and behavioral intentions of the people in Yunlin County with different environmental sensitivities (degree of vulnerability/value of EF). The relationship among risk cognition, local attachment to place, and behavioral intention was firstly studied by using stratified random sampling and questionnaire surveys. The relationships among these factors were analyzed using the structural equation method.

The questionnaire is divided into five parts. The first part concerns attitudes to climate change, including climate change awareness, pro-nature values and guilt, and an evaluation of environmental problems. The second part concerns risk perceptions, and asks the respondents about environmental safety, health, and natural disasters. The third part concerns the relationship between degree of place attachment, the integration of the respondents into their communities, and their places of residence. The fourth part concerns behavioral intention, awareness of mitigation actions, and the actions of the respondents to adapt to climate change. The fifth part concerns basic data, including the socioeconomic background of individuals, such as age, sex, education, occupation, residence, personal annual income, the number of disasters experienced, and the type and amount of transportation used.

This study used the stratified random sampling questionnaire survey. The respondents were selected from townships with four types of environmental sensitivity ("high degree of synthesized 
vulnerability/high EF", "low synthesized vulnerability/low EF," high synthesized vulnerability/low $\mathrm{EF}^{\prime}$, and "low synthesized vulnerability/high $\mathrm{EF}^{\prime}$ ). The number of population in the four townships was calculated, and the number of villages was allocated according to the proportion of the population. This survey was set in the confidence interval of $95 \%$, and accuracy is $\pm 5 \%$. According to the number of questionnaires allocated to the four townships, a total of 582 effective samples were collected. Interviews were conducted by interviewers in person. Among them, the "high degree of synthesized vulnerability/high EF" (Huwei) had 135 effective samples, the "low degree of synthesized vulnerability/low EF (Linnei) had 148 effective samples, the "high degree of synthesized vulnerability /low EF" (Sihu) had 150 effective samples, and the "low degree of synthesized vulnerability/high EF" (Mailiao) had 149 valid samples.

\subsection{Structural Equation Model (SEM)}

The structural equation modeling (SEM) can be used to deal with complex and multivariate research data. It was formally proposed in 1987, which can effectively integrate the two major techniques of statistics: factor analysis and path analysis. SEM is a collection of statistical techniques that allow a set of relationships between one or more independent variables-either continuous or discrete- and one or more dependent variables-either continuous or discrete- to be investigated [63]. SEM can be used to confirm the relationship between observed variables and potential variables. SEM can deal with numerous types of measurement models: composites, common factors, and causal-formative measurement; it also explains the differences between these types of measurement models and sorts out any possible ambiguity regarding formative endogenous constructs [64]. Moreover, the characteristic of SEM is that it can explain the causal relationship between the variable and the strain quantity by way of a road map. Nowadays, research about SEM starts to transform because some questions, such as for example, the biggest challenge to testing moderation hypotheses in SEM, is the complexity underlying the modeling of latent variable interactions [65]. To solve this problem, researchers integrate SEM and partial least squares path modeling (PLS), which has gained increasing dissemination in marketing [66].

Based on literature reviews, hypotheses about SEM paths are presented. As shown in Table 1, the hypotheses concerning SEM are based on factor analysis and seek to verify the measurement model of measurement variables in each dimension. Path analysis was performed to verify the structure model of each dimension to test whether each path is supported by the hypotheses. Path analysis was carried out to compare the paths of SEMs in areas of different sensitivities to elucidate the relationships among climate change attitudes and knowledge, risk perceptions, place attachment, mitigation, and adaptation behavior.

As can be seen in Figure 2, the five circles represent the core concept of this study, including climate change attitudes and knowledge, risk perceptions, place attachment, mitigation, and adaptation behavioral intentions. The square represents the specific measurement that is used to explain the concept, and is also the topic of the research questionnaire. Arrows point to causal relationships, and numbers represent positive or negative coefficients and the size of coefficients. For example, $\mathrm{H} 1$ represents "climate change attitudes and knowledge directly affects climate change mitigation behavioral intention". H3 stands for "climate change attitudes and knowledge through intermediate factors (place attachment) indirectly affects climate change mitigation behavioral intention". 
Table 1. Path Hypotheses.

\begin{tabular}{|c|c|c|}
\hline Path Hypotheses & References & Path Number \\
\hline $\begin{array}{l}\text { Climate change attitudes and } \\
\text { knowledge directly affect climate } \\
\text { change mitigation behavioral } \\
\text { intention }\end{array}$ & Ajzen and Fishbein (1975) & H1 \\
\hline $\begin{array}{l}\text { Climate change attitudes and } \\
\text { knowledge directly affect climate } \\
\text { change adaptive behavioral } \\
\text { intention }\end{array}$ & Ajzen and Fishbein (1975) & $\mathrm{H} 2$ \\
\hline $\begin{array}{l}\text { Climate change attitudes and } \\
\text { knowledge indirectly influence } \\
\text { climate change mitigation } \\
\text { behavioral intention through place } \\
\text { attachment }\end{array}$ & Scannell and Gifford (2010) & $\mathrm{H} 3$ \\
\hline $\begin{array}{l}\text { Climate change attitudes and } \\
\text { knowledge indirectly affect } \\
\text { climate change adaptation } \\
\text { behavioral intention through place } \\
\text { attachment }\end{array}$ & Scannell and Gifford (2010) & $\mathrm{H} 4$ \\
\hline $\begin{array}{l}\text { Disaster risk perceptions directly } \\
\text { affects climate change mitigation } \\
\text { behavioral intention }\end{array}$ & Liao (2009) & H5 \\
\hline $\begin{array}{l}\text { Disaster risk perceptions directly } \\
\text { affects climate change adaptation } \\
\text { behavioral intention }\end{array}$ & Jou and Shih (2000) & H6 \\
\hline $\begin{array}{l}\text { Disaster risk perceptions indirectly } \\
\text { influences climate change } \\
\text { mitigation behavioral intention } \\
\text { through place attachment }\end{array}$ & $\begin{array}{c}\text { Scannell \& Gifford (2010), Scannell and Gifford (2013), } \\
\text { Bernardo (2013), Bonaiuto et al. (2011), Casakin et al. (2015), } \\
\text { Hatfield and Job (2001), Devine-Wright (2009, 2013), Fried (2000), } \\
\text { De Dominicis et al. (2015), Gifford et al. (2009), Schultz et al. (2014) }\end{array}$ & $\mathrm{H} 7$ \\
\hline $\begin{array}{l}\text { Disaster risk perceptions indirectly } \\
\text { affect climate change-related } \\
\text { adaptation behavioral intention } \\
\text { through place attachment }\end{array}$ & $\begin{array}{l}\text { Scannell and Gifford (2010), Scannell and Gifford (2013), } \\
\text { Bernardo (2013), Bonaiuto et al. (2011), Casakin et al. (2015), } \\
\text { Hatfield and Job (2001), Devine-Wright (2009, 2013), Fried (2000), } \\
\text { De Dominicis et al. (2015), Gifford et al. (2009), Schultz et al. (2014) }\end{array}$ & $\mathrm{H} 8$ \\
\hline
\end{tabular}

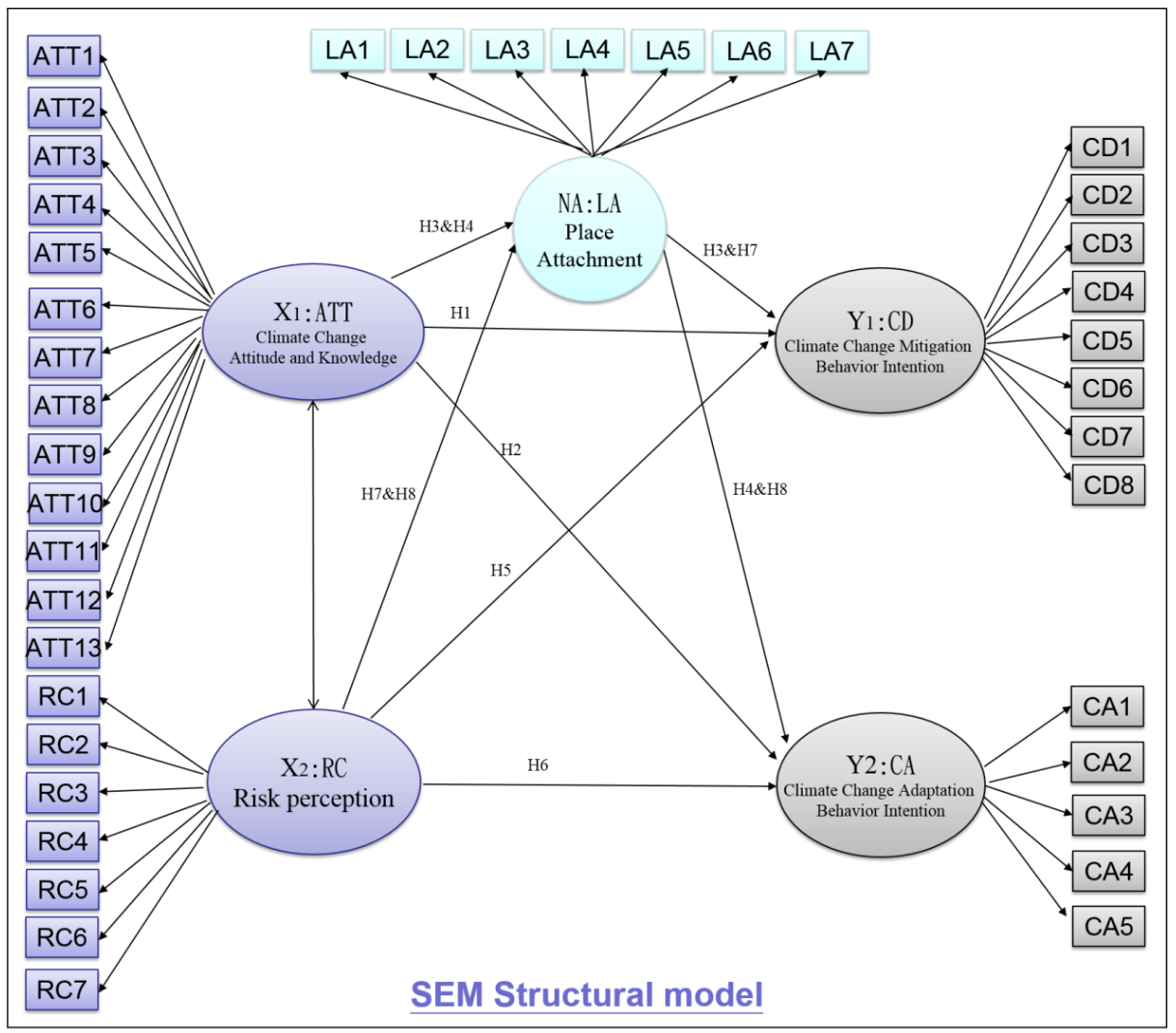

Figure 2. A structured equation model of attitudes to climate change, risk perceptions, place attachment, and behavioral intentions. 


\section{Results}

Respondents aged 21-25 years old accounted for $25.9 \%$ of the total sample; those aged less than 20 years old accounted for $22.7 \%$. A large number of the elderly people refused to answer the questionnaire, so the sampled respondents were mostly young. Respondents aged under 20 years represented $41.2 \%$ of the total sample in Linnei township, and respondents aged 21-25 years old accounted for $51.1 \%$ of the sample in Huwei township, perhaps because Huwei Technology University was located close to these two townships. The female and male respondents accounted for $50.9 \%$ and $49.1 \%$ of the sample, respectively. In 2015 , females constituted $48.6 \%$ and males constituted $51.4 \%$ of the population of the sampled townships of Huwei, Linnei, Mailiao, and Sihu. The overall sex ratio of the samples very is close to that of the population in Yunlin County, indicating that the opinions of the sampled respondents plausibly represented those of the population.

The highest percentage of respondents had "no disaster experience;" comprising 36.7\% in Sihu, $78.4 \%$ in Linnei, $60.4 \%$ in Mailiao, and $60 \%$ in Huwei. The percentage who had "no disaster experience" in Sihu Township was the lowest among the townships of all four types, in which $31.3 \%$ of respondents had "experienced one disaster" and 21\% had "experienced two or three disasters", indicating that respondents in Sihu had experienced the disasters more frequently than the others. Sihu was in the category "high synthesized vulnerability/low EF", indicating that this area is more likely to suffer from disasters.

A conceptual causal relationship model of attitudes to climate change, risk perceptions, and mitigation adaptation behavior is constructed. The research hypotheses and conceptual causal relationship model are validated empirically. The empirical study areas are Sihu, Linnei, Mailiao, and Huwei townships, in which questionnaire surveys are conducted, and resulting data are analyzed using SEM. The SEM analyses are divided into confirmatory factor analysis (CFA) and path analysis. CFA and path analysis are used herein to verify the measurement model and the structure model. Relevant results follow.

\subsection{Analysis of Areas of Different Sensitivities Using SEM}

To determine whether differently sensitive areas exhibit different causal relationships among attitudes to climate change, risk perceptions and mitigation/adaptation behavior, Huwei (high synthesized vulnerability/high EF), Linnei (low synthesized vulnerability/low EF), Sihu (high synthesized vulnerability/low EF), and Mailiao (low synthesized vulnerability/high EF) are used as empirical study areas (Table 2). Based on the causal relationship among attitudes to climate change, risk perceptions, place attachment, and mitigation/adaptation behavior (Figure 1), the structure of the models of areas with different sensitivities is analyzed.

Table 2. Sensitivity categories for Yunlin County based on synthesized vulnerability and ecological footprint (EF).

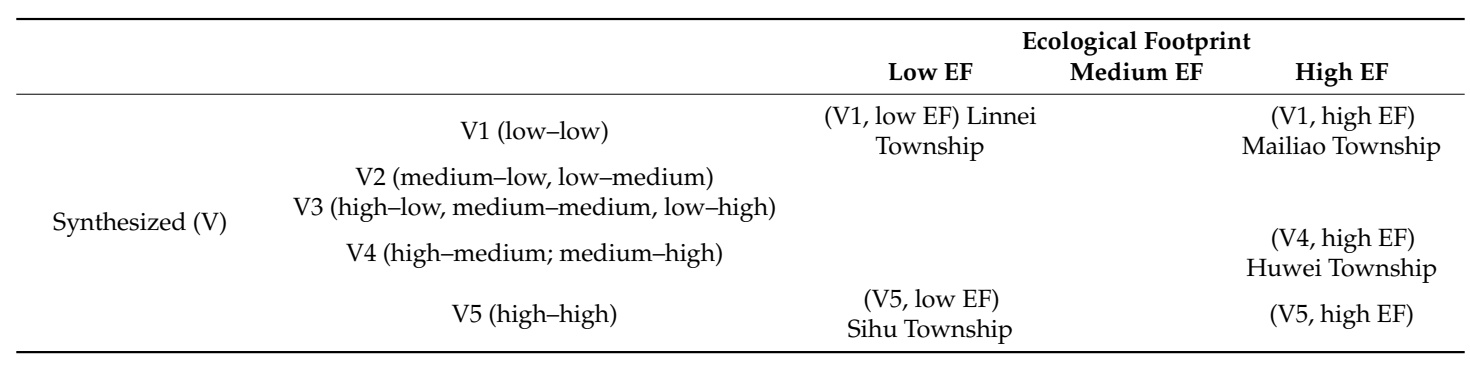

\subsubsection{Sihu Township}

Sihu is a township with "high synthesized vulnerability" and "low EF". Figure 3 displays the causal relationship among attitudes to and knowledge of climate change, risk perceptions, 
and mitigation/adaptation behavioral intentions. From the SEM results, "attitudes to and knowledge of climate change" positively affects "place attachment". The impact coefficient is 0.06 .

Through the influence of place attachment, "attitudes to and knowledge of climate change" indirectly affects "climate change-mitigation behavioral intention" with an impact coefficient of $0.01(0.06 \times 0.09=0.0054)$. Through place attachment, "attitudes to and knowledge of climate change" indirectly affects "climate change-related adaptation behavioral intention" with an impact coefficient of $0.02(0.06 \times 0.25=0.015)$. "Attitudes to and knowledge of climate change" directly affects "climate change-mitigation behavioral intention", with an impact coefficient of 0.28 . "Attitudes to and knowledge of climate change" also directly affects "climate change-related adaptation behavioral intention", with an impact coefficient of 0.57 .

"Disaster risk perceptions" directly affects "attitudes to and knowledge of climate change", and indirectly influences "climate change-mitigation behavioral intention" and "climate change-related adaptation behavioral intention". "Disaster risk perceptions" positively affects "place attachment", with an impact coefficient of 0.2. Through "place attachment", "disaster risk perceptions" indirectly affects "climate change-mitigation behavioral intention", with an impact coefficient of 0.02 $(0.2 \times 0.09=0.018)$. Through "place attachment", "disaster risk perceptions" indirectly affects "climate change-related adaptation behavioral intention", with an impact coefficient of $0.05(0.2 \times 0.25=0.05)$. "Disaster risk perceptions" directly affects "climate change-related adaptation behavioral intention", with an impact coefficient of 0.39 . "Disaster risk perceptions" negatively affects "climate change-related adaptation behavioral intention" with an impact coefficient of 0.32 .

According to the path relationships for Sihu, people's attitudes to and knowledge of climate change influence their mitigation and adaptation behavioral intentions more than the other paths (impacts); risk perceptions affect mitigation behavioral intentions more than the other paths. However, risk perceptions have little effect on place attachment. These results imply that Sihu residents understand the meaning of climate change, mitigate climate change, take actions to reduce the effects of climate change, and work on their pre-disaster preparedness. Furthermore, residents understand that disasters affect the environment, economy, and society, and take necessary steps to reduce the impact of climate change on these things; however, their own pre-disaster preparedness is not thereby enhanced. Since Sihu Township is a highly vulnerable area, its residents should be more responsive to disasters than they currently are to reduce the damage due to disasters.

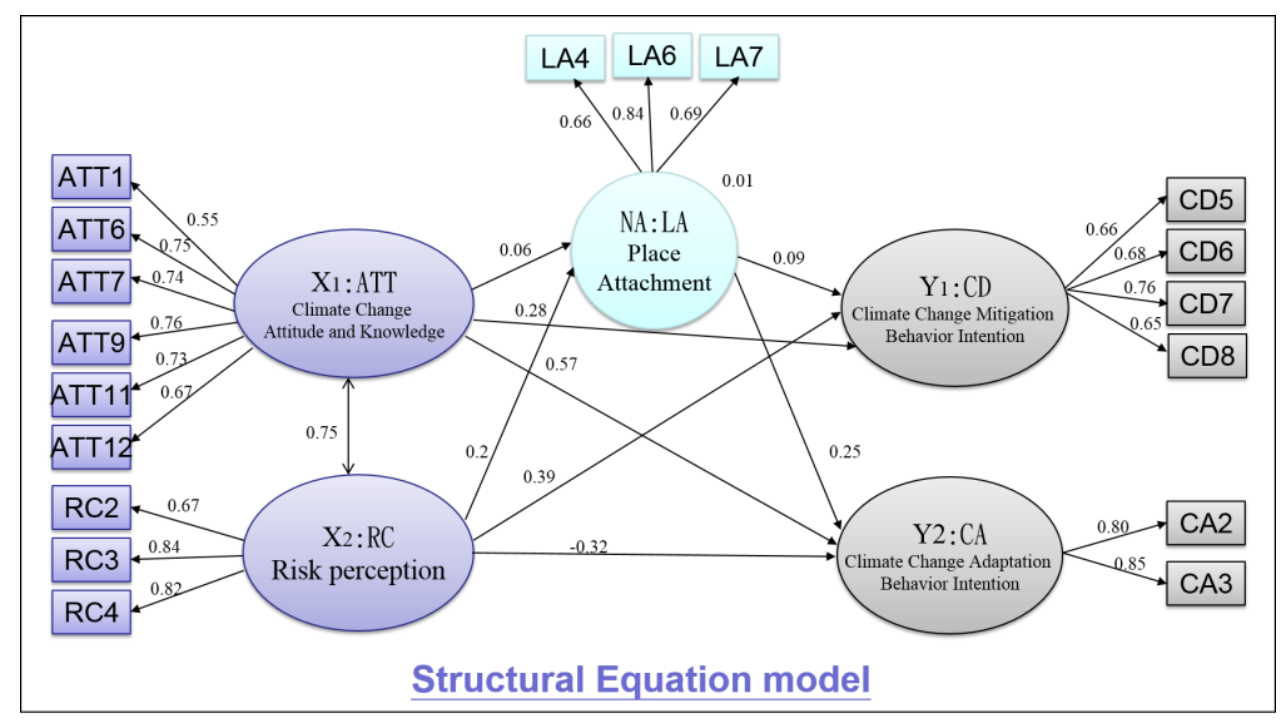

Figure 3. Structural equation model for Sihu Township. 


\subsubsection{Linnei Township}

Linnei is a township with "low synthesized vulnerability and low EF". Figure 4 presents the causal relationship among attitudes to and knowledge of climate change, risk perceptions, and mitigation/adaptation behavioral intentions. From the SEM results, "attitudes to and knowledge of climate change" positively affects "place attachment", with an impact coefficient is 0.32 . Through "place attachment", "disaster risk perceptions" indirectly affects "climate change-mitigation behavioral intention", with an impact coefficient of $0.03(0.32 \times 0.09=0.0288)$. Through "place attachment", "disaster risk perceptions" indirectly affects "climate change-related adaptation behavioral intention", with an impact coefficient of $0.06(0.32 \times 0.18=0.0576)$.

"Attitudes to and knowledge of climate change" directly affects "climate change-mitigation behavioral intention" (with an impact coefficient of 0.46) and "climate change-related adaptation behavioral intention" (with an impact coefficient of 0.13). "Disaster risk perceptions" directly influences "attitudes to and knowledge of climate change", and indirectly influences "climate change-mitigation behavioral intention" and "climate change-related adaptation behavioral intention".

"Disaster risk perceptions" directly affects "climate change-related adaptation behavioral intention", with an impact coefficient of 0.03. "Disaster risk perceptions" directly affects "climate change-related adaptation behavioral intention", with an impact coefficient of 0.29. "Disaster risk perceptions" negatively affects "place attachment", with an impact coefficient of -0.4 . Through "place attachment", "perceived risk of disaster" indirectly affects "climate change-mitigation behavioral intention", with an impact coefficient of $-0.00(-0.04 \times 0.09=-0.0036)$. Through "place attachment", "perceived risk of disaster" indirectly affects "climate change-related adaptation behavioral intention", with an impact coefficient of $-0.01(-0.04 \times 0.18=-0.0072)$.

According to Linnei's path relationships, people's attitudes to and knowledge of climate change affect mitigation and adaptation behavioral intentions more than the other paths (impacts); risk perceptions affect mitigation behavioral intentions more strongly than the other paths. However, risk perceptions have little influence on place attachment. These results imply that Linnei residents understand the meaning of climate change, mitigate climate change, take further actions to cope with climate change issues, and improve their pre-disaster preparedness. Furthermore, residents realize that disasters affect the environment, economy, and the society, and take actions to reduce the effects of climate change. Linnei township has the weakest relationship between attitudes to and knowledge of climate change and disaster risk perceptions among the townships in all four categories, which warrants further exploration.

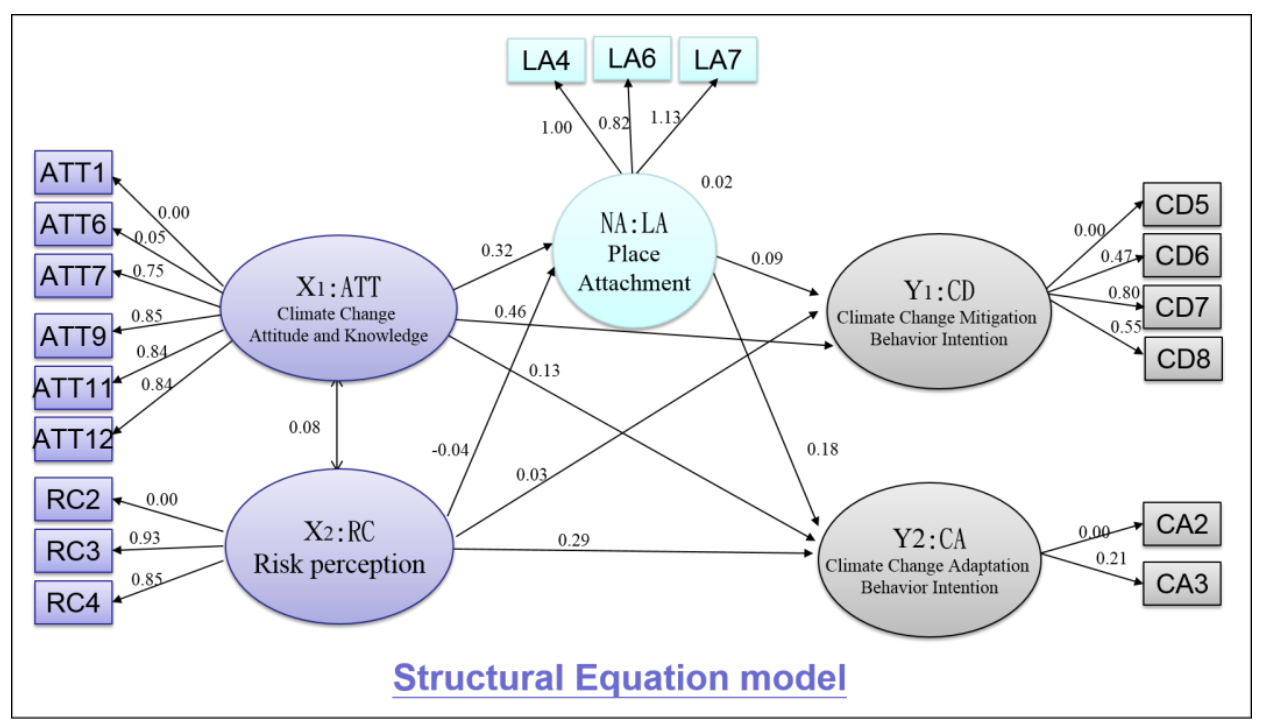

Figure 4. Structural equation model for Linnei Township. 


\subsubsection{Mailiao Township}

Mailiao is a township with "low synthesized vulnerability" and "high EF". Figure 5 presents the causal relationship among attitudes to and knowledge of climate change, risk perceptions, and mitigation/adaptation behavioral intentions. From the SEM results, "attitudes to and knowledge of climate change" positively affects "place attachment", with an impact coefficient of 0.19 . Through "place attachment", "disaster risk perceptions" indirectly affects "climate change-mitigation behavioral intention", with an impact coefficient of $0.03(0.19 \times 0.15=0.0285)$. Through "place attachment", "disaster risk perceptions" indirectly affects "climate change-related adaptation behavioral intention", with an impact coefficient of $0.02(0.19 \times 0.09=0.0171)$. "Attitudes to and knowledge of climate change" directly affects "climate change-mitigation behavioral intention" (with an impact coefficient of 0.16) and "climate change-related adaptation behavioral intention" (with an impact coefficient of 0.44). "Disaster risk perceptions" directly affects "attitudes to and knowledge of climate change" and indirectly influences "climate change-mitigation behavioral intention" and "climate change-related adaptation behavioral intention".

"Disaster risk perceptions" positively affects "climate change-related adaptation behavioral intention", with an impact coefficient of 0.33 . "Disaster risk perceptions" negatively influences "climate change-related adaptation behavioral intention", with an impact coefficient of -0.32 . "Disaster risk perceptions" negatively affects "place attachment", with an impact coefficient of -0.12 . Through "place attachment", "disaster risk perceptions" indirectly affects "climate change-mitigation behavioral intention", with an impact coefficient of $-0.02(-0.12 \times 0.15=-0.018)$. Through "place attachment", "disaster risk perceptions" indirectly affects "climate change-related adaptation behavioral intention", with an impact coefficient of $-0.01(-0.12 \times 0.09=-0.0108)$.

According to Mailiao's path relationships, people's attitudes to and knowledge of climate change influence mitigation and adaptation behavioral intentions more than the other paths (impacts); risk perceptions affect mitigation behavioral intentions more strongly than the other paths. However, risk perceptions have little influence on place attachment. These results imply that Mailiao residents understand the meaning of climate change, mitigate it, take further climate-related actions, and work on their pre-disaster preparedness. Additionally, residents realize that disasters affect the environment, economy, and the society, and take necessary actions to reduce the impact of climate change. However, pre-disaster preparedness is not thereby enhanced. Mailiao township is in an area with a low synthesized vulnerability and high individual EF, so residents' ability to respond to disasters may be highly susceptible to a lack of risk awareness.

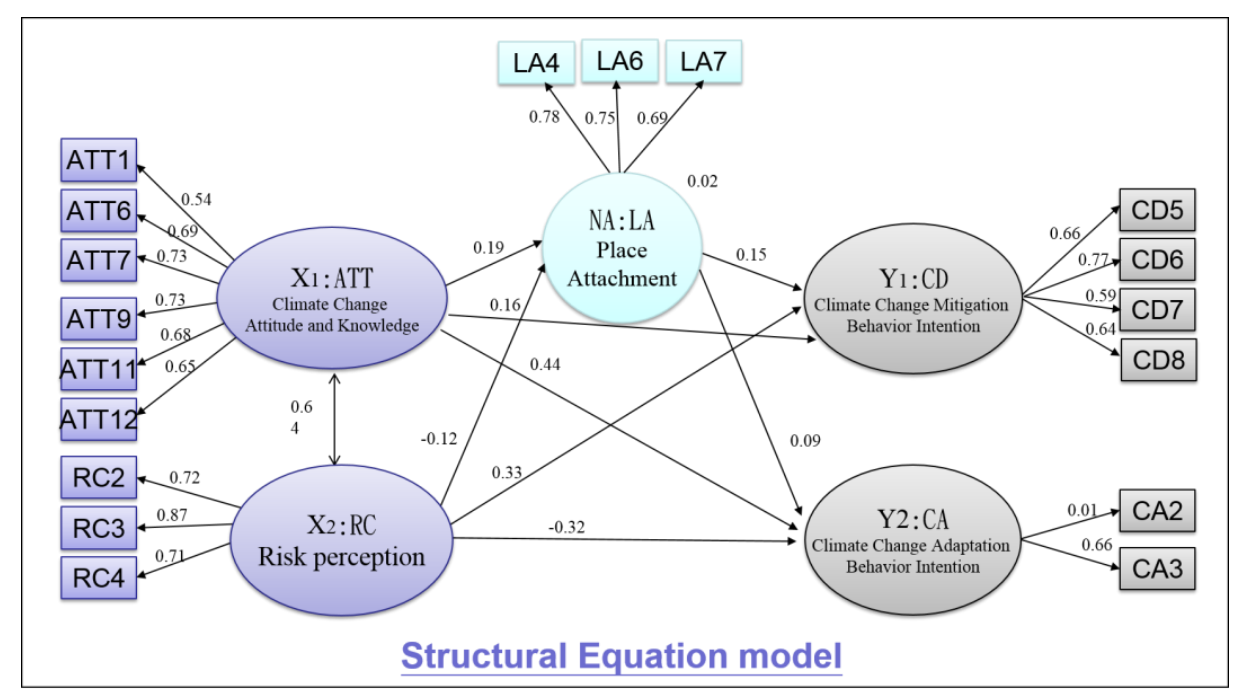

Figure 5. Structural equation model for Mailiao Township. 


\subsubsection{Huwei Township}

Huwei is a township with "high synthesized vulnerability" and "high EF". Figure 6 shows the causal relationship among attitudes to and knowledge of climate change, risk perceptions, and mitigation/adaptation behavioral intention. From the SEM results, "attitudes to and knowledge of climate change" positively affects "place attachment", with an impact coefficient of 0.31 . Through "place attachment", "disaster risk perceptions" indirectly affects "climate change-mitigation behavioral intention", with an impact coefficient of $0.00(0.31 \times 0.01=0.0031)$. Through "place attachment", "disaster risk perceptions" indirectly affects "climate change-related adaptation behavioral intention", with an impact coefficient of $0.03(0.31 \times 0.10=0.03)$. "Attitudes to and knowledge of climate change" directly and positively affects "climate change-mitigation behavioral intention" (with an impact coefficient of 0.16) and "climate change-related adaptation behavioral intention" (with an impact coefficient of 0.03). "Disaster risk perceptions" directly influences "attitudes to and knowledge of climate change" and indirectly influences "climate change-mitigation behavioral intention" and "climate change-related adaptation behavioral intention".

"Disaster risk perceptions" directly and positively affects "climate change-mitigation behavioral intention" (with an impact coefficient of 0.31) and "climate change-related adaptation behavioral intention" (with an impact coefficient of 0.36). "Disaster risk perceptions" negatively influences "place attachment" with an impact coefficient of -0.25 . Through "place attachment", "disaster risk perceptions" indirectly affects "climate change-mitigation behavioral intention", with an impact coefficient of $-0.00(-0.25 \times 0.01=-0.0025)$. Through "place attachment", "disaster risk perceptions" indirectly affects "climate change-related adaptation behavioral intention", with an influence coefficient of $-0.03(-0.25 \times 0.10=-0.025)$.

According to Huwei's path relationships, people's attitudes to and knowledge of climate change influence mitigation and adaptation behavioral intentions less strongly than the other paths (impacts). Risk perceptions affect mitigation behavioral intentions and adaptation behavioral intention most strongly than the other paths. However, risk perceptions have little influence on place attachment. These results imply that Huwei residents understand the meaning of climate change, mitigate climate change, take actions to reduce the effects of climate change, and work on their pre-disaster preparedness. Furthermore, they realize that disasters affect the environment, economy, and the society, and take necessary actions to reduce the impact of climate change.

Huwei township is located in a region with high synthesized vulnerability and high EF; residents exhibit mitigation and adaptation behavior. Additionally, perhaps because Huwei Township is located in a highly vulnerable area, its residents have had more experiences of disasters than others.

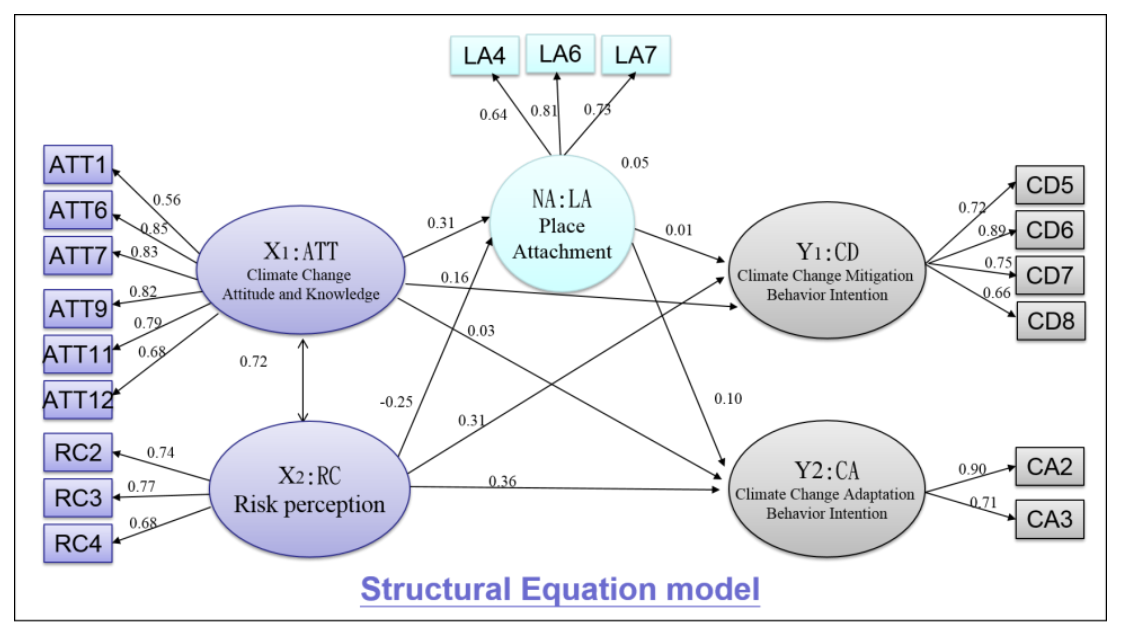

Figure 6. Structural equation model for Huwei township. 


\subsection{Comparison of SEMs in Areas of Different Sensitivities}

This investigation elucidates whether the path coefficients of SEMs of attitudes to and knowledge of climate change, risk perceptions, and climate change-related behavioral intentions are statistically significant for the four types of sensitive areas. Table 3 presents the difference in the SEMs of areas in the four categories of sensitivity.

Table 3. Comparison of Path Differences in Areas of Different Types of Sensitivity. ATT: attitudes to and knowledge of climate change; CA: climate change-related adaptation behavioral intention.

\begin{tabular}{|c|c|c|c|c|c|c|}
\hline \multirow[t]{2}{*}{ Model } & \multirow{2}{*}{$\begin{array}{l}\Delta \text { DF } \\
\text { Sihu v }\end{array}$} & \multirow[t]{2}{*}{$\Delta \mathrm{CMIN}$} & \multirow[t]{2}{*}{$\mathbf{P}$} & \multicolumn{2}{|c|}{ Townships } & \multirow[t]{2}{*}{ Large Influence Coefficient } \\
\hline & & & & Sihu & Linnei & \\
\hline ATT to LA & 1 & 0.657 & 0.418 & & & \\
\hline ATT to CD & 1 & 0.282 & 0.595 & & & \\
\hline ATT to CA & 1 & 5.873 & $0.015^{*}$ & 0.58 & 0.11 & Sihu \\
\hline $\mathrm{RC}$ to $\mathrm{CD}$ & 1 & 3.466 & 0.063 & & & \\
\hline $\mathrm{RC}$ to $\mathrm{CA}$ & 1 & 5.280 & $0.022 *$ & -0.32 & 0.20 & Linnei \\
\hline LA to CD & 1 & 0.007 & 0.934 & & & \\
\hline \multirow[t]{2}{*}{ LA to CA } & 1 & 0.598 & 0.439 & & & \\
\hline & \multicolumn{2}{|c|}{ Mailiao vs. Huwei } & & Mailiao & Huwei & \\
\hline ATT to LA & 1 & 0.056 & 0.812 & & & \\
\hline ATT to CD & 1 & 0.001 & 0.981 & & & \\
\hline ATT to CA & 1 & 5.168 & $0.023 *$ & 0.44 & 0.03 & Mailiao \\
\hline $\mathrm{RC}$ to $\mathrm{CD}$ & 1 & 0.009 & 0.926 & & & \\
\hline $\mathrm{RC}$ to $\mathrm{CA}$ & 1 & 9.377 & $0.002 *$ & -0.31 & 0.36 & Huwei \\
\hline \multirow[t]{2}{*}{ LA to CD } & 1 & 0.749 & 0.387 & & & \\
\hline & \multicolumn{2}{|c|}{ Sihu vs. Huwei } & & Sihu & Huwei & \\
\hline ATT to LA & 1 & 0.872 & 0.351 & & & \\
\hline ATT to CD & 1 & 0.212 & 0.645 & & & \\
\hline ATT to CA & 1 & 4.379 & $0.036^{*}$ & 0.58 & 0.00 & Sihu \\
\hline $\mathrm{RC}$ to $\mathrm{CD}$ & 1 & 0.056 & 0.813 & & & \\
\hline $\mathrm{RC}$ to $\mathrm{CA}$ & 1 & 6.828 & $0.009 *$ & -0.32 & 0.38 & Huwei \\
\hline LA to $C D$ & 1 & 0.271 & 0.603 & & & \\
\hline \multirow[t]{2}{*}{ LA to CA } & 1 & 0.741 & 0.389 & & & \\
\hline & \multicolumn{2}{|c|}{ Linnei vs. Mailiao } & & Linnei & Mailiao & \\
\hline ATT to LA & 1 & 0.003 & 0.953 & & & \\
\hline ATT to CD & 1 & 1.155 & 0.282 & & & \\
\hline ATT to CA & 1 & 6.629 & $0.010 *$ & 0.13 & 0.43 & Mailiao \\
\hline $\mathrm{RC}$ to $\mathrm{CD}$ & 1 & 2.702 & 0.100 & & & \\
\hline $\mathrm{RC}$ to $\mathrm{CA}$ & 1 & 7.968 & $0.005 *$ & 0.20 & -0.31 & Linnei \\
\hline LA to $C D$ & 1 & 0.121 & 0.728 & & & \\
\hline \multirow[t]{2}{*}{ LA to CA } & 1 & 0.142 & 0.707 & & & \\
\hline & \multicolumn{2}{|c|}{ Linnei vs. Huwei } & & Linnei & Huwei & \\
\hline ATT to LA & 1 & 0.042 & 0.837 & & & \\
\hline ATT to CD & 1 & 1.148 & 0.284 & & & \\
\hline ATT to CA & 1 & 0.082 & 0.774 & & & \\
\hline $\mathrm{RC}$ to $\mathrm{CD}$ & 1 & 2.327 & 0.127 & & & \\
\hline $\mathrm{RC}$ to $\mathrm{CA}$ & 1 & 0.412 & 0.521 & & & \\
\hline LA to CD & 1 & 0.388 & 0.533 & & & \\
\hline \multirow[t]{2}{*}{ LA to CA } & 1 & 0.073 & 0.787 & & & \\
\hline & \multicolumn{2}{|c|}{ Sihu vs. Mailiao } & & Sihu & Mailiao & \\
\hline ATT to LA & 1 & 0.458 & 0.499 & & & \\
\hline ATT to CD & 1 & 0.202 & 0.653 & & & \\
\hline ATT to CA & 1 & 0.059 & 0.808 & & & \\
\hline $\mathrm{RC}$ to $\mathrm{CD}$ & 1 & 0.136 & 0.713 & & & \\
\hline $\mathrm{RC}$ to $\mathrm{CA}$ & 1 & 0.123 & 0.726 & & & \\
\hline LA to CD & 1 & 0.156 & 0.693 & & & \\
\hline LA to CA & 1 & 1.004 & 0.316 & & & \\
\hline
\end{tabular}


No significant differences exist among the four types of townships ("high synthesized vulnerability/low EF" (Sihu), "low synthesized vulnerability/high EF" (Mailiao), "medium-high synthesized vulnerability/high EF" (Huwei), and "low synthesized vulnerability/low EF" (Linnei)). However, significant differences exist in the path from "attitudes to and knowledge of climate change" (ATT) to "climate change-related adaptation behavioral intention" (CA), and from "disaster risk perceptions" (RC) to "climate change-related adaptation behavioral intention" (CA). Moreover, the large influence coefficients of the path from "attitudes to and knowledge of climate change" (ATT) to "climate change-related adaptation behavioral intention" (CA), and from "disaster risk perceptions" (RC) to "climate change-related adaptation behavioral intention" (CA), have the opposite sign. Restated, when the path coefficient from "attitudes to and knowledge of climate change" (ATT) to "climate change-related adaptation behavioral intention" (CA) is larger in one area than in another, then the path coefficient from "disaster risk perceptions" (RC) to "climate change-related adaptation behavioral intention" (CA) is smaller than in the other areas.

Other than the paths compared above, no pair of paths exhibits significant differences. These results reveal that other than the path from "attitudes to and knowledge of climate change" (ATT) to "climate change-related adaptation behavioral intention" (CA) and from "disaster risk perceptions" (RC) to "climate change-related adaptation behavioral intention" (CA), the causal relationship among attitudes to and knowledge of climate change, risk perceptions, and climate change-mitigation and adaption behavioral intentions are not affected by the degree of vulnerability or the size of EF.

The above results may arise from the difficulty (or reluctance) of the elderly to answer the questionnaire, lowering the respondents' average age. Younger respondents had fewer experiences of the impact of climate change and natural disasters than the elderly, affecting the validity of the questionnaire. Furthermore, only three questions were related to climate change adaptation behavioral intentions, also potentially affecting the analysis. Table 3 presents the relationships between "synthesized vulnerable and $\mathrm{EF}$ " and the two paths from "attitudes to and knowledge of climate change" (ATT) to "climate change-related adaptation behavioral intention" (CA)" and from "disaster risk perceptions" (RC) to "climate change-related adaptation behavioral intention" (CA).

\subsubsection{No Significant Variation with EF}

(1) Low EF: Sihu versus Linnei (high synthesized vulnerability versus low synthesized vulnerability)

Table 3 demonstrates that with regard to the impact of "attitudes to and knowledge of climate change" on "climate change-related adaptation behavioral intention" (ATT to CA), Sihu (high synthesized vulnerability) exhibited a greater impact than Linnei (low synthesized vulnerability) with a difference of 0.47 units per unit. The impact of "disaster risk perceptions" on "climate change-related adaptation behavioral intention" (RC to CA) in Sihu (high synthesized vulnerability) was negative (with an influence coefficient of -0.32 ), whereas it was positive $(0.20)$ in Linnei (low synthesized vulnerability).

The above results imply that owing to the low individual EF, residents of Sihu (high synthesized vulnerability) have a high coefficient for the path from "attitudes to and knowledge of climate change" to "adaptation behavioral intention", but a negative coefficient for the path from "disaster risk perceptions" to "adaptation behavioral intention". In areas with high vulnerability, residents should have a sense of the crisis that may be caused by a natural disaster, and in the future, whether residents of areas of high vulnerability have inadequate disaster risk awareness should be investigated. Additionally, residents of Linnei (low synthesized vulnerability) have a low coefficient for the path from "attitudes to and knowledge of climate change" to "adaptation behavioral intention". Although the synthesized vulnerability is low, the coefficient of the path from "disaster risk perceptions" to "adaptation behavioral intention" is relatively high, indicating that the preparedness of residents in Linnei is adequate. 
(2) High EF: Mailiao versus Huwei (high synthesized vulnerability versus low synthesized vulnerability)

Table 3 suggests that the impact of "attitudes to and knowledge of climate change" on "climate change-related adaptation behavioral intention" (ATT to CA) is higher in Mailiao (high synthesized vulnerability) than in Huwei (low synthesized vulnerability), with a difference of 0.41 units per unit. The impact of "disaster risk perceptions" on "climate change-related adaptation behavioral intention" (RC to CA) in Mailiao (high synthesized vulnerability) is negative (with an impact coefficient of -0.31 ), whereas it is positive (0.36) in Huwei (low synthesized vulnerability).

The above results imply that owing to the high individual EF, residents of Mailiao (with high synthesized vulnerability) have a high coefficient for the path from "attitudes to and knowledge of climate change" to "adaptation behavioral intention", but a negative coefficient for the path from "disaster risk perceptions" to "adaptation behavioral intention". In areas with high vulnerability, residents should have a sense of the crisis that can be caused by a disaster, and in the future, whether residents in areas of high vulnerability have inadequate disaster risk awareness should be explored. Furthermore, the relevant authorities should propose strategies to increase awareness of the need to adapt to potential disasters. Residents of Linnei (with low synthesized vulnerability) have a low coefficient for the path from "attitudes to and knowledge of climate change" to "adaptation behavioral intention". Although the synthesized vulnerability is relatively low, the coefficient of the path from "disaster risk perceptions" to "adaptation behavioral intention" is relatively high, indicating that the preparedness of residents of Linnei is adequate.

\subsubsection{Same Level of Synthesized Vulnerability}

(1) High synthesized vulnerability: Huwei versus Sihu (high EF versus low EF)

Table 3 suggests that the impact of "attitudes to and knowledge of climate change" on "climate change-related adaptation behavioral intention" (ATT to CA) is lower in Huwei (high EF) than in Sihu (low EF), with a difference of 0.58 units per unit. The impact of "disaster risk perceptions" on "climate change-related adaptation behavioral intention" (RC to CA) in Huwei (high EF) is positive (with an impact coefficient of 0.38 ), whereas that in Sihu (low EF) is negative $(-0.32)$.

The above results imply that for a given degree of high synthesized vulnerability, residents of Mailiao (high EF) have a low coefficient for the path from "attitudes to and knowledge of climate change" to "adaptation behavioral intention", and have a positive coefficient for the path from "disaster risk perceptions" to "adaptation behavioral intention". Residents of areas with higher EF typically consume more land and water resources $[67,68]$. In the future, whether residents of areas with high synthesized vulnerability/high EF have an inadequate awareness of disaster risk awareness should be examined. Relevant authorities should propose strategies to increase awareness of the need to adapt to potential disasters. Residents of Sihu (low EF) have a high coefficient for the path from "attitudes to and knowledge of climate change" to "adaptation behavioral intention". Although Sihu has a low $\mathrm{EF}$, the path coefficient from disaster risk perceptions to adaptation behavioral intentions is negative, indicating that the residents of Sihu are less prepared than the other districts to cope with disasters.

(2) Low synthesized vulnerability: Mailiao versus Linnei (high EF versus low EF)

Table 3 suggests that the impact of "attitudes to and knowledge of climate change" on "climate change-related adaptation behavioral intention" (ATT to CA) is higher in Mailiao (high EF) than in Linnei (low EF), with a difference of 0.30 units per unit. The impact of "disaster risk perceptions" on "climate change-related adaptation behavioral intention" (RC to CA) in Mailiao (high EF) is negative (with an impact coefficient of -0.31), whereas in Linnei (low EF), it is positive (0.20).

The above results imply that with the same level of a fixed low synthesized vulnerability, residents of Mailiao (high EF) have a high coefficient of the path from "attitudes to and knowledge of climate change" to "adaptation behavioral intention", but have a negative coefficient of the path from "disaster 
risk perceptions" to "adaptation behavioral intention". Residents of areas with higher EF normally consume more land and water resources. In the future, whether residents of areas with low synthesized vulnerability/high EF have inadequate disaster risk awareness should be investigated. Relevant authorities should propose strategies to increase awareness of the need to adapt to potential disasters. Residents of Linnei (low EF) have a low coefficient of the path from "attitudes to and knowledge of climate change" to "adaptation behavioral intention". Although the synthesized vulnerability is low, the coefficient of the path from "disaster risk perceptions" to "adaptation behavioral intention" is relatively high, indicating that the preparedness of residents of Linnei is adequate.

\section{Conclusions and Suggestions}

\subsection{Conclusions}

In this study, 582 questionnaires were collected in Yunlin County to examine the relationship among attitudes to and knowledge of climate change, disaster risk perceptions, and climate change-mitigation and adaptation behavioral intentions. Since many elderly people refused to answer the questionnaire, the sampled contained a large proportion of young people. However, the ratio of males to females was very similar to that of the population of Yunlin. Respondents from Sihu had experienced many disasters, which is consistent with the region's high synthesized vulnerability. Other than the lack of senior citizens, the sample herein was consistent with the basic socioeconomic distribution in Yunlin County. The refusal of the elderly to answer the questionnaire can be overcome by improving ability of the researchers and obtaining support from village/neighborhood heads.

Sihu residents are aware of climate change and willing to take actions to mitigate its impact, and they prepare to do so before disasters hit. Sihu residents are also willing to mitigate the impact of climate change by taking actions in response to their experiences of disasters. Since Sihu is a township with high synthesized vulnerability, people should be more prepared to cope with potential disasters there than elsewhere. Linnei residents, who are aware of climate change, are willing to mitigate it and take relevant actions. Additionally, Linnei residents are willing to work on pre-disaster preparedness as a result of their personal experiences of the impact of disasters. Linnei has the lowest path coefficients in the SEMs of attitudes to and knowledge of climate change, disaster risk perceptions, climate change-mitigation, and the adaptation behavioral intentions of the four sampled townships. This warrants further exploration.

Mailiao residents are aware of the impact of climate change owing to their experiences of disasters, and are willing to improve their preparedness to mitigate it. Mailiao is a township with low synthesized vulnerability and high EF. Its residents' ability to cope with disasters may be susceptible to a lack of awareness of crises owing to the low level of synthesized vulnerability. Huwei residents, having experienced the effects of disasters, and for the sake of mitigating climate change, are willing to improve their preparedness for disasters. Huwei is a region with high synthesized vulnerability and high EF. Although residents of Huwei have more experiences of disasters than those of other townships, they will only take mitigation actions after experiencing disasters, suggesting that the response to disasters in this township is relatively passive.

Most of the paths of the SEMs in the four sampled areas exhibited no significant differences, and the sensitivity of the area mostly did not affect them. Furthermore, the SEM of mitigation behavioral intentions was unaffected by the type of vulnerability. However, adaptation behavioral intentions varied with the type of vulnerability and affected the path coefficient from "attitudes to and knowledge of climate change" and "disaster risk perceptions" to "climate change-related adaptation behavior". This result suggests that residents of areas of different sensitivities exhibit different adaptation behaviors, perhaps as a result of differences in attitudes to and knowledge of climate change, disaster risk perceptions, experiences of regional disasters, and socioeconomic characteristics.

According to different types of environmental sensitivity, this study investigates adaptation strategies for different climatic changes, types of vulnerability, attitudes to and knowledge of climate 
change, disaster risk perceptions, experiences of regional disasters, socioeconomic background, and other factors. Future studies can also try to develop effective climate change-related adaptation strategies and improve public attitudes to and knowledge of climate change and disaster risk, in order to increase mitigation and adaptation behaviors.

\subsection{Suggestions}

Based on a review of the literature, this study proposes a conceptual framework of causal relationships among attitudes to and knowledge of climate change, disaster risk perceptions, and mitigation/adaptation behavioral intentions. It also investigates the effects of attitudes to and knowledge of climate change and disaster risk perceptions on mitigation and adaptation behavioral intentions and their relationships with place attachment. As mentioned above, the mitigation of, and adaptation to, the effects of climate change should be improved by continuously increasing disaster risk perceptions and further affecting mitigation/adaptation behaviors. Therefore, people's perception of the risks associated with climate change should be continuously improved and whether doing so can effectively encourage climate change-related mitigation and adaptation behavior should be examined. Understanding people's perceptions of climate change-related risk and assessing whether they meet people's needs by being constantly revised is important in order to support local mitigation and adaptation strategies.

\subsubsection{Socioeconomic Background}

The refusal of elderly people to answer the questionnaire was the main reason for the concentration of the lower age groups in the sample. This refusal has two possible causes. First, the questionnaire was for academic purposes. Although the researchers tried to word it to be easily understandable, some questions were still difficult for the elderly to answer. Even though the questions could be answered orally rather than by writing, many of the elderly still felt the process to be cumbersome and refused to participate. Secondly, many elderly people speak only Taiwanese (rather than Mandarin), and most of the interviewees were young students who were less proficient in Taiwanese, resulting in communication barriers and further increasing the refusal of the elderly to participate in the study. Follow-up studies should involve repeated visits to elderly people with interviewers who speak Taiwanese and with voice recorders, or work with the village office to contact them to increase their willingness to participate.

\subsubsection{Comparison of SEMs across Areas of Different Sensitivities}

Whether the causal relationships among attitudes to and knowledge of climate change, disaster risk perceptions and mitigation/adaptation behavioral intentions varied with the type of sensitivity of the area to climate change warrants further exploration. Follow-up studies should be conducted in different counties and cities using a similar approach to the one used herein. The resulting comparisons and discussions will provide a clearer understanding of the causal relationships among attitudes to and knowledge of climate change, disaster risk perceptions, and mitigation/adaptation behavioral intentions, to help the relevant authorities improve the efficiency of climate change-mitigation and adaptation mechanisms. Furthermore, such comparisons can help areas of different sensitivity to develop appropriate strategies for adapting to and mitigating climate change.

\subsubsection{Risk Governance Strategy under High Vulnerability}

Yunlin County is located in a high-sensitivity area, with high synthesized vulnerability and high EF. After the development of SEMs of attitudes to and knowledge of climate change, disaster risk perceptions and mitigation/adaptation behavioral intentions, appropriate risk governance strategies should be investigated in order to cope with various climate-related hazards in different environmentally sensitive areas. Appropriate strategies should be proposed based on both biophysical vulnerability and social vulnerability. Briefly, conservation and adaptation measures should be the 
priority in environmentally sensitive areas and areas with high synthesized vulnerability. Furthermore, in highly vulnerable areas, disaster prevention and resilience should be the main concerns in infrastructure construction, and no-regret adaptation strategies should be adopted. The no-regret strategies refer to when implementing climate change mitigation or adaptation, the goal set is simple, with no cost or low cost, and saving money without spending money. It is expected to appeal to people in a flexible manner to respond to low-carbon living habits and achieve greenhouse gas reduction effects.

Acknowledgments: The author would like to thank the Ministry of Science and Technology of the Republic of China, Taiwan, for financially supporting this research under contract MOST 105-2410-H-170-001-MY2.

Conflicts of Interest: The author declares no conflicts of interest.

\section{References}

1. IPCC. Climate Change 2014. Mitigation of Climate Change Summary for Policymakers and Technical Summary; IPCC: Geneva, Switzerland, 2014.

2. Marigi, S.N. Climate change vulnerability and impacts analysis in Kenya. Am. J. Clim. Chang. 2017, 6, 52-74. [CrossRef]

3. The Royal Society. Royal Society and US National Academy of Sciences Release Joint Publication on Climate Change. Available online: https:/ /royalsociety.org/news/2014/climate-change-evidence-causes/ (accessed on 18 July 2018).

4. World Bank. Managing the Impacts of Climate Change on Poverty. Available online: http:/ / www.worldbank. org/en/news/infographic/2015/11/08/managing-the-impacts-of-climate-change-on-poverty (accessed on 18 July 2018).

5. World Economic Forum. Global Risks Report 2016. Available online: http://reports.weforum.org/globalrisks-2016/ (accessed on 18 July 2018).

6. Zanetti, V.B.; Sousa Junior, W.C.; Freitas, D.M.D. A Climate Change Vulnerability Index and Case Study in a Brazilian Coastal City. Sustainability 2016, 8, 811. [CrossRef]

7. IPCC. In Climate Change 2014: Synthesis Report; IPCC: Geneva, Switzerland, 2014.

8. Eckstein, D.; Kunzel, V.; Schafer, L. Global Climate Risk Index 2018; Germanwatch e.V.: Bonn, Germany, 2017.

9. UNISDR. Global Assessment Report on Disaster Risk Reduction; United Nations International Strategy for Disaster Reduction: Geneva, Switzerland, 2015.

10. De Dominicis, S.; Fornara, F.; Cancellieri, U.G.; Twigger-Ross, C.; Bonaiuto, M. We are at risk, and so what? Place attachment, environmental risk perceptions and preventive coping behaviours. J. Environ. Psychol. 2015, 43, 66-78. [CrossRef]

11. Devine-Wright, P.; Batel, S. My neighbourhood, my country or my planet? The influence of multiple place attachments and climate change concern on social acceptance of energy infrastructure. Glob. Environ. Chang. 2017, 47, 110-120. [CrossRef]

12. Slovic, P. Perception of Risk. Science 1987, 236, 280-285. [CrossRef] [PubMed]

13. Terpstra, T.; Gutteling, J.M.; Geldof, G.D.; Kappe, L.J. The perception offlood risk and water nuisance. Water Sci. Technol. 2006, 54, 431-439. [CrossRef] [PubMed]

14. Bennett, N.J.; Dearden, P.; Murray, G.; Kadfak, A. The capacity to adapt? Communities in a changing climate, environment, and economy on the northern Andaman coast of Thailand. Ecol. Soc. 2014, 19, 5. [CrossRef]

15. Kelman, I. Climate Change and the Sendai Framework for Disaster Risk Reduction. Int. J. Disaster Risk Sci. 2015, 6, 117-127. [CrossRef]

16. Lee, Y.-J. Building resilient cities through community empowerment: Principles and strategies for Taiwan. Int. Rev. Spat. Plan. Sustain. Dev. 2017, 5, 35-46. [CrossRef]

17. Lee, Y.-J. A synthesized biophysical and social vulnerability assessment for Taiwan. IOP Conf. Ser. Earth Environ. Sci. 2017, 94, 012161. [CrossRef]

18. Silva, J.A.; Eriksen, S.; Ombe, Z.A. Double exposure in Mozambique's Limpopo River Basin. Geogr. J. 2010, 1, 6-24. [CrossRef] 
19. Lee, Y.-J.; Tung, C.-M.; Lin, S.-C. Carrying capacity and ecological footprint of Taiwan. In Advances in Energy and Environment Research; Achour, B., Wu, Q., Eds.; Taylor \& Francis Group: London, UK, 2017; pp. 207-218. [CrossRef]

20. National Safety Council. Injury Facts, 2013 ed.; National Safety Council: Itasca, IL, USA, 2013.

21. NIST (National Institute of Standards and Technology). Community Resilience Planning Guide for Buildings and Infrastructure Systems (Volume II); NIST Special Publication 1190; NIST: Washington, DC, USA, 2016.

22. Tierney, K. The Social Roots of Risk: Producing Disasters, Promoting Resilience; Stanford University Press: Stanford, CA, USA, 2014.

23. The National Academies. Disaster Resilience: A National Imperative; National Academies Press: Washington, DC, USA, 2012.

24. Raaijmakers, R.; Krywkow, J.; van der Veen, A. Flood risk perceptions and spatial multi-criteria analysis: An exploratory research for hazard mitigation. Natl. Hazards 2008, 46, 307-322. [CrossRef]

25. Brun, W. Cognitive components in risk perception: Natural versus manmade risks. J. Behav. Decis. Mak. 1992, 5, 117-132. [CrossRef]

26. Zhou, S.H.; Shih, H.C. Study on the Public Perception of Earthquake Hazard Mitigation in Decision-Making for Environmental Risk Management. City Plan. 2000, 27, 363-380.

27. Liao, K.M. Analysis of People's Disaster Preparedness from the Perspective of Risk Cognition-Taking Earthquake Disaster as an Example. Sci.-Tech. Policy Rev. 2009, 2, 76-82.

28. Craparo, G.; Gori, A.; Petruccelli, I.; Cannella, V.; Simonelli, C. Intimate partner violence: Relationships between alexithymia, depression, attachment styles, and coping strategies of battered women. J. Sex. Med. 2014, 11, 1484-1494. [CrossRef] [PubMed]

29. Gifford, R.; Scannell, L.; Kormos, C.; Smolova, L.; Biel, A.; Boncu, S. Temporal pessimism and spatial optimism in environmental assessments: An 18-nation study. J. Environ. Psychol. 2009, 29, 1-12. [CrossRef]

30. Radcliffe, N.M.; Klein, W.M.P. Dispositional, unrealistic, and comparative optimism: Differential relations with the knowledge and processing of risk information and beliefs about personal risk. Pers. Soc. Psychol. Bull. 2002, 28, 836-846. [CrossRef]

31. Schultz P, W.; Milfont T, L.; Chance R, C.; Tronu, G.; Luís, S.; Ando, K. Cross-cultural evidence for spatial bias in beliefs about the severity of environmental problems. Environ. Behav. 2014, 46, 267-302. [CrossRef]

32. Bonnes, M.; Lee, T.; Bonaiuto, M. Psychological Theories for Environmental Issues; Ashgate: Aldershot, UK, 2003.

33. Manzo, L.C.; Devine-Wright, P. Place Attachment: Advances in Theory 2014, Methods and Applications; Routledge: New York, NY, USA, 2014.

34. Van Veelen, B.; Haggett, C. Uncommon ground: The role of different place attachments in explaining community renewable energy projects. Sociol. Rural. 2017, 57, 533-554. [CrossRef]

35. Creswell, T. Place: A Short Introduction; Routledge: London, UK, 2003.

36. Fried, M. Grieving for a lost home. In The Urban Condition; Duhl, L.J., Ed.; Basic Books: New York, NY, USA, 1963; pp. 151-171.

37. Bowlby, J. A Secure Base; Routledge: London, UK, 1988.

38. Gustafson, P. Place attachment in an age of mobility. In Place Attachment: Advances in Theory, Method and Application; Manzo, L., Devine-Wright, P., Eds.; Routledge: Oxon, UK, 2014; pp. 37-48.

39. Lewicka, M. In search of roots: Memory as an enabler of place attachment. In Place Attachment: Advances in Theory, Method and Application; Manzo, L., Devine-Wright, P., Eds.; Routledge: Oxon, UK, 2014; pp. 59-60.

40. Keller, C.; Siegrist, M.; Gutscher, H. The role of the affect and availability heuristics in risk communication. Risk Anal. 2006, 26, 631-639. [CrossRef] [PubMed]

41. Slovic, P.; Finucane, M.L.; Peters, E.; MacGregor, D.G. Risk as analysis and risk as feelings: Some thoughts about affect, reason, risk, and rationality. Risk Anal. 2004, 24, 311-322. [CrossRef] [PubMed]

42. Slovic, P.; Fischhoff, B.; Lichtenstein, S. Accident probabilities and seat belt usage: A psychological perspective. Accid. Anal. Prev. 1978, 10, 281-285. [CrossRef]

43. Bird, D.K.; Gisladottir, G.; Dominey-Howes, D. Different communities, different perspectives: Issues affecting residents' response to a volcanic eruption in southern Iceland. Bull. Volcanol. 2011, 73, 1209-1227. [CrossRef]

44. Brown, B.; Altman, L.; Werner, C.M. International encyclopedia of housing and home. In Place Attachment; Smith, S.J., Ed.; Elsevier: New York, NY, USA, 2012. 
45. Casakin, H.; Hernández, B.; Ruiz, C. Place attachment and place identity in Israeli cities: The influence of city size. Cities 2015, 42, 224-230. [CrossRef]

46. Khima, I.; Phearanich, H. Climate resilience in rural Cambodia: Adaptation mainstreaming, water resource management and agricultural practice. Asian J. Environ. Disaster Manag. 2012, 4, 447-468.

47. Hong, J.C.; Fu, H.Y. A Study on the Pro-Environmental Behavioral Intention of Post-Secondary School Students. Bull. Educ. Psychol. 2012, 44, 373-387.

48. Ajzen, I. From intentions to actions: The theory of planned behavior. In Action Control; Springer: Berlin/Heidelberg Germany, 1985; pp. 11-39.

49. Ajzen, I. The theory of planned behavior. Organ. Behav. Hum. Decis. Process. 1991, 50, 179-211. [CrossRef]

50. Kaiser, F.G.; Oerke, B.; Bogner, F.X. Behavior-based environmental attitude: Development of an instrument for adolescents. J. Environ. Psychol. 2007, 27, 242-251. [CrossRef]

51. Yang, C.H.; Lin, Y.C. Values, Cognition and Con-greenhouse-effect Behaviors-Empirical Test of the Taipei Metropolitan Area. City Plan. 2010, 37, 13-45.

52. Benassi, V.A.; Overson, C.; Hakala, C.M. Applying Science of Learning in Education: Infusing Psychological Science into the Curriculum. Available online: http://teachpsych.org/ebooks/asle2014/index.php (accessed on 18 July 2018).

53. Doswald, N.; Osti, M. Ecosystem-Based Approaches to Adaptation and Mitigation-Goodpractice Examples and Lessons Learned in Europe; Federal Ministry of Environment, Nature Conservation and Nuclear Safety: Bonn, Germany, 2011; pp. 3-4.

54. Halady, I.R.; Rao, P.H. Does awareness to climate change lead to behavioral change? Int. J. Clim. Chang. Strateg. Manag. 2010, 2, 6-22. [CrossRef]

55. Bonaiuto, M.; De Dominicis, S.; Fornara, F.; Ganucci Cancellieri, U.; Mosco, B. Flood risk: the role of neighborhood attachment. In Urban Flood Risk Management, Approaches to Enhance Resilience of Communities, Proceedings of the International Symposium UFRIM; Zen, G., Hornich, R., Eds.; Verlag der Technischen Universität Graz: Graz, Austria, 2011; pp. 547-558.

56. Mishra, S.; Mazumdar, S.; Damodar, S. Place attachment and flood pre-paredness. J. Environ. Psychol. 2010, 30, 187-197. [CrossRef]

57. Ruiz, C.; Hernandez, B. Emotions and coping strategies during an episode of volcanic activity and their relations to place attachment. J. Environ.-Ment. Psychol. 2014, 38, 279-287. [CrossRef]

58. Armas, I. Earthquake risk perception in Bucharest, Romania. Risk Anal. 2006, 26, 1223-1234. [CrossRef] [PubMed]

59. Bonaiuto, M.; Breakwell, G.M.; Cano, I. Identity processes and environ-mental threat: The effects of nationalism and local identity upon perception of beach pollution. J. Community Appl. Soc. Psychol. 1996, 6, 157-175. [CrossRef]

60. Gifford, R. Environmental psychology matters. Annu. Rev. Psychol. 2014, 65, 541-579. [CrossRef] [PubMed]

61. Scannell, L. The Bases of Bonding: The Psychological Functions of Place Attachment in Comparison to Interpersonal Attachment. Ph.D. Thesis, University of Victoria, Victoria, BC, Canada, 2013. Available online: https: / / dspace.library.uvic.ca/ / handle/1828/5074 (accessed on 18 July 2018).

62. Scannell, L.; Gifford, R. Defining place attachment: A tripartite organizing framework. J. Environ. Psychol. 2010, 30, 289-297. [CrossRef]

63. Ullman, J.B.; Bentler, P.M. Structural Equation Modeling. Res. Methods Psychol. 2012, 2, 661-690.

64. Henseler, J. Bridging Design and Behavioral Research with Variance-Based Structural Equation Modeling. J. Advert. 2017, 46, 178-192. [CrossRef]

65. Sardeshmukh, S.R.; Vandenberg, R.J. Integrating Moderation and Mediation: A Structural Equation Modeling Approach. Organ. Res. Methods 2017, 20, 721-745. [CrossRef]

66. Hair, J.F.; Hult, G.T.M.; Ringle, C.M.; Sarstedt, M.; Thiele, K. Mirror, Mirror on the Wall: A Comparative Evaluation of Composite-Based Structural Equation Modeling Methods. J. Acad. Mark. Sci. 2017, 45, 616-632. [CrossRef] 
67. Lee, Y.-J. Social vulnerability indicators as a sustainable planning tool. Environ. Impact Assess. Rev. 2014, 44, 31-42. [CrossRef]

68. Lee, Y.-J.; Lin, S.-C.; Chen, C.-C. Mapping cross-boundary climate change vulnerability-Case study of the Hualien and Taitung Area, Taiwan. Sustainability 2016, 8, 64. [CrossRef] 